\title{
Beiträge zur Kenntniss der Helophoren aus Europa und den angrenzenden Ländern.
}

Von A. Kuwert in Wernsdorf. (Ostpreussen.)

(Fortsetzung.)

10. Helophorus griseus var. montenegrinus mihi.

Eine ganz dunkle Varietät, metallisch schwarzgrün, die Flügeldecken nach den Seitenrändern heller grau schattirend. Die Palpen ganz dunkel, jedoch mit dicker Spindel, wie bei dem norddeutschen griseus Er., Schenkel und Schienen braun, Tarsen dunkler. Flügeldecken hinter der Schulter stark eingedrückt. Es ist späteren Ermittlungen anheimzugeben, ob das Thier nicht Artrechte beanspruchen kann.

\section{Helophorus affinis Marsh. und Erichsoni Bach.}

Durch die Vielfältigkeit der Varietäten des granularis L. (brevicollis Thoms.), welche ich bei dem umfangreichsten Material zu constatiren Gelegenheit gehabt, halte ich doch für zweifelhaft, ob als affinis Marsh. nicht nur eine Varietät von brevicollis Thoms. beschrieben wurde, welche dem affinis sprechend ähnlich aussieht. Um Irrungen zu vermeiden, würde ich rathen, den Namen Erichsoni beizubehalten und verweise auf die von mir beschriebenen Varietäten von granularis in den Bestimmungstabellen. Es sind übrigens die Varietäten von granularis von denen von Erichsoni beim Vergleiche der Füsse leicht durch die stärkeren und längeren Tarsen und besonders durch die längeren Krallen, die Erichsoni hat, zu unterscheiden.

\section{Helophorus Seidlitzii n. sp.}

Oblongus, subtus niger, capite, prothorace elytrisque viridiaeneis; palpis maxillaribus articulo ultimo elongato, testaceis, ultimo articulo apice nigro-infuscato; pedibus testaceis. Prothorace sulcis mediis internis in medio prothorace subito evidenter flexuosis, externis autem prothoracis margini haud parallelis; interstitiis internis paene glabratis, externis plus minus granulatis, sulco medio foveolato. Elytris post humerum depressis, punctato-striatis, apicem corporis valde superantibus, interstitiis nec carinatis, neque elevatis. Prothorace latitudine corporis, sed ante obtusos angulos posteriores paullo minore latitudine. Species ab Helophoro gra nu la ri Lin. colore aeneo et depressione elytrorum longitudineque eorum discedens; ceteris in rebus granulari simillima. Long. $2.5 \mathrm{~mm}$. 
Wohl sicher eigene Art. Die Schienen des Thieres sind auf der Aussenseite stärker beborstet, als die von granularis Lin., mit welchem dasselbe die meiste Aehnlichkeit im Körperbau hat. Auch die stark niedergedrückten Flügeldecken hinter der Schulter, sowie der weniger gewölbte Halsschild trennen die Thiere von einander, ebenso die bei Seidlitzii compacteren Tarsengelenke. Die Exemplare stammen aus Portugal.

\section{Helophorus Reitteri n. sp.}

Testaceus, subtus niger, pedibus palpisque testaceis, his apice infuscatis, capite et prothorace obscurioribus submetallescentibus, hoc latissime flavo-marginato, sulcis paene rectis, exterioribus in anteriore prothoracis parte a margine antice extenso rotundatoque remotis, omnibus interstitiis fere glabratis, sed subopacis, vix granulatis, capite ante oculos angustato, quare antice fere quadrato. Elytris non fortiter punctato-striatis, interstitiis non elevatis, parvulis punctulis singulis irregulariter impressis, fere in lineam positis ; testaceis, macula nigra communi dorsali post medium, juxta utrimque macula minore, etiam margine posteriore externo nigro-signatis, post medium paullulum dilatatis. Corpore paullo majore, quam aeneipennis Thoms., a quo discedit quadrato anteriore capite, colore, rectis prothoracis sulcis, prothorace antice magis dilatato, lateribus ejusdem latius et constanter flavomarginatis, tarsis omnibus crassioribus. Long. $4 \mathrm{~mm}$. Ex Graecia a Parnasso.

Dass diese zweifellos neue Art bisher noch keinen Beschreiber fand, gibt Zeugniss für die grosse Verwirrung, die bisher in der Familie der Helophoren obwaltete, sowie für den Mangel richtiger Bestimmungstabellen. Von dem ihm allein nahestehenden aeneipennis ist das Thier leicht durch den flacheren Thorax, der vorne bedeutend breiter und ausserdem seitlich sehr breit gelb gerandet ist, wie bei keiner anderen Species, durch den vorne viereckigen Kopfschild, sowie die anscheinend möglich constante Zeichnung mit tief schwarzer Pfeilmakel, davor seitwärts mit je einem schwarzen Punkte und besonders durch den dunklen hinteren Seitenrand der Flügeldecken leicht zu unterscheiden.

Vier Stücke vom Parnass.

\section{Helophorus asturiensis n. sp.}

Brunneus, subtus niger, pedibus palpisque testaceis, capite prothoraceque aeneis; hoc antice lateribusque angustissime flavomarginato, sulcis externis rectis, prothoracis marginibus non paral- 
lelis, sulcis internis medio leniter flexuosis, sulco medio haud foveolato. Elytris duplo longioribus quam latis, brunneis, fortiter punctatostriatis, punctis angustissime coordinatis, interstitiis fere planis et duplo punctis latioribus, praesertim tertio quintoque punctulis singulis minutissimis impressis. Prothorace multo angustiore elytris, quare valde discedit ab aeneipenni Thoms. Tarsorum pedum anteriorum articulo ultimo apice crassiusculo quadrupla longitudine primi articuli parvulisque ungulis. Long. $3 \cdot 5-4 \mathrm{~mm}$.

Asturia.

Der schmale Halsschild, die braune Farbe der Flügeldecken, der Bau der Tarsen, besonders der Vorderfüsse, an denen sämmtliche anderen Glieder gleich kurz, das Klauenglied dagegen besonders entwickelt, dick und lang ist, unterscheidet diese Art, von der leider nur ein Stück vorliegt, leicht von den verwandten Arten und von dem kleineren aeneipennis.

\section{Helophorus strigifrons Thoms. und laticollis Thoms.}

Beide Arten sind von mir hierselbst in Mehrzahl gefangen. Allgemein wurde hier die gemeinere Art für laticollis gehalten. Erst der Umstand, dass ich in der Reitter'schen und Sejdlitz'schen Sammlung die hiesige gemeinere Art als strigifrons durch Sahlberg benannt fand, führte mich zu näherer Untersuchung an der Hand der Thomson'schen Beschreibungen. So sonderbar es erscheinen mag, es liess sich aus der lateinischen Diagnose der Unterschied, wenigstens an den hiesigen Exemplaren, nicht durchgreifend feststellen. Nur aus dem Umstande, dass es bei H.laticollis heisst: "lateralibus sulcis fere margini parallelis" und bei strigifrons: "lateralibus margini haud parallelis", bei laticollis ferner: "palpis maxillaribus articulo ultimo, quam penultimo haud transverso duplo longiore" und bei strigifrons: "articulo ultimo crassitie sua quadruplo longiore, penultimo oblongo", lässt auf die Richtigkeit der Sahlberg'schen Bestimmung schliessen. Die unbedingt das Richtige treffende Behaarung der Beine und Tarsen hat Thomson nicht berücksichtigt. Uebrigens haben einige Stücke der bisher für laticollis gehaltenen Art eine fein gestrichelte Stirne, worauf wohl der Name strigifrons zurückzuführen sein dürfte, während andere daselbst glatt oder mit kleinen Grübchen versehen sind. Der Breite des Halsschildes nach, welcher bei dem Sa h lb e r g'schen strigifrons vorne viel mehr verbreitert ist, als bei dem anderen Thiere, müssten die Namen eher umgetauscht werden.

"Wiener Entomologische Zeitung" IV. (30. October 1885). Heft 9. 
264 A. K uwert: Beiträge z. Kenntniss d. Helophoren aus Europa etc.

16. Helophorus pumilio Thoms. und var. Redtenbacheri mihi.

Die in Süd- und Mitteleuropa vorkommenden Stücke der im Norden Deutschlands nicht gerade seltenen Species zeigen eine so beträchtliche Abweichung in der etwas geringeren Verbreiterung des Halsschildes, dem schmäleren Habitus, den mehr kielförmigen Intervallen der Flügeldecken, welche manchmal sogar noch abwechselnd scharf erhöht sind, dass ich für diese südliche, T h o m s o n nicht vorgelegene Varietät den Namen Redtenbacheri vorzuschlagen mir erlaube, weil dieselbe sicherlich Red te $\mathrm{nbacher}$ für seine Fauna austriaca vorgelegen hat.

\section{Helophorus maroccanus n. sp.}

Brunneo-testaceus, subtus nigro-testaceus, pedibus palpisque testaceis; prothorace fere elytris angustiore, ante medium paullo dilatato, lateribus paene rectis, sulcis lateralibus intermediis in medio leniter flexuosis, postice paullo minus quam antice discedentibus, externis rectis sulcis prothoracis margini non parallelis; elytris profunde punctatostriatis, paulo ante finem latissimis, postice prominulis ; interstitiis prothoracis intermediis haud fortiter, externis fortius granulatis; elytrorum interstitiis planis, singulis ciliis ornatis; tarsis tibiisque omnibus, his in externo margine longissime albociliatis, quare et corpore paulo ante finem latissimo minusque ante ultimum finem diminuta latitudine discedit ab Hel. Erichsoni, cui corpus post medium latissimum est cujusque tarsi tibiaeque brevioribus criniti sunt ciliis; maxime autem discedit ciliis singulis in interstitiis elytrorum positis. Long. $3 \mathrm{~mm}$.

Marocco.

Die zwar in demselben Verhältniss gebauten, doch etwas kürzeren Fussglieder und die hellen Klauen, die hin und wieder bewimperten Interstitien der Flügeldecken, die stärkeren Punktreihen derselben, die lange Bewimperung sämmtlicher Tarsen und Schienen mit feinen Seidenhärchen von halber Schienenlänge, die Verbreiterung des Körpers bei $3 / 4$ der Flügellänge kennzeichnen die Art von dem verwandten Erichsoni. Ein Stück aus Marocco.

$\mathrm{Ob}$ diese Art nicht gleich ist dem von Motschulsky aufgezählten angustatus Motsch. und aegyptiacus Motsch. lässt sich bei der Art der Beschreibung, wie der Autor sie uns in Schrenk's Reisen S. 105 vorführt, nicht genau feststellen. Die beiden Species stammten aus Egypten. 


\section{$2 \mathrm{BHL}$ Biodiversity Heritage Library}

Kuwert, August Ferdinand. 1885. "Beiträge zur Kenntniss der Helophoren aus Europa und den angrenzenden Ländern. Fortsetzung." Wiener entomologische Zeitung 4, 261-264. https://doi.org/10.5962/bhl.part.20135.

View This Item Online: https://www.biodiversitylibrary.org/item/44101

DOI: https://doi.org/10.5962/bhl.part.20135

Permalink: https://www.biodiversitylibrary.org/partpdf/20135

\section{Holding Institution}

Smithsonian Libraries

\section{Sponsored by}

Smithsonian

\section{Copyright \& Reuse}

Copyright Status: NOT_IN_COPYRIGHT

This document was created from content at the Biodiversity Heritage Library, the world's largest open access digital library for biodiversity literature and archives. Visit BHL at https://www.biodiversitylibrary.org. 